\title{
Mixed effects of ant-aphid mutualism on plants across different spatial scales
}

\author{
Shuang Zhang, Yuxin Zhang, Keming Ma* \\ State Key Laboratory of Urban and Regional Ecology, Research Center for Eco-Environmental Sciences, Chinese \\ Academy of Sciences, Beijing 100085, PR China
}

Received 12 October 2014; accepted 3 April 2015

Available online 13 April 2015

\begin{abstract}
Scale affects how we observe, explain, and predict patterns and processes in ecology. The pattern of biotic interactions can be scale-dependent, but it is not clear how biotic interactions perform at different scales. We tested the effects of aphid-tending ants Lasius fuliginosus on the oak tree Quercus liaotungensis by excluding ants at two scales (branches and whole trees). Furthermore, we explored the variation of the effects on different-size branches and trees. The ants had significant anti-herbivory effects, a positive effect on aphids, but a negative effect on galls. Contrary to previous assumptions, effects of ants on plants and herbivores are similar between the branch and plant scales. The size of the branch or tree also had no impact on the ecological effects of ants, indicating the ecological effect of ant-aphid mutualism is consistent within and among individual trees. The homogeneous distribution of aphids may be the key reason for the scale-independent effect of the indirect ant-plant interaction. Our finding highlights the importance of biotic defense for plants across different spatial scales.
\end{abstract}

\section{Zusammenfassung}

Der räumliche Maßstab beeinflusst, wie wir ökologische Muster und Prozesse beobachten, erklären und vorhersagen. Das Muster biotischer Interaktionen kann von der räumlichen Skala abhängen, aber es ist nicht klar, wie biotische Interaktionen auf unterschiedlichen Skalen funktionieren. Wir untersuchten die Einflüsse der blattlausbesuchenden Ameise Lasius fuliginosus auf Eichenbäumen (Quercus liaotungensis), indem wir Ameisen auf zwei räumlichen Ebenen (Äste und ganze Bäume) ausschlossen. Darüber hinaus untersuchten wir die Variabilität des Einflusses auf Ästen bzw. Bäumen unterschiedlicher Größe. Die Ameisen hatten einen signifikant negativen Effekt auf die Herbivorie, einen positiven Effekt auf die Blattläuse aber einen negativen auf Gallen. Im Gegensatz zu früheren Annahmen, waren die Effekte der Ameisen auf Herbivore und Pflanzen für die Ast-Skala und die Baum-Skala ähnlich. Die Größe der Äste und Bäume hatte ebenfalls keinen Einfluss auf die ökologischen Wirkungen der Ameisen, was anzeigt, dass der ökologische Effekt des Ameise-Blattlaus-Mutualismus' innerhalb und zwischen einzelnen Bäumen gleichartig ist. Die gleichmäßige Verteilung der Blattläuse könnte der Hauptgrund für die Skalenunabhängigkeit des Effekts der indirekten Ameise-Pflanze-Beziehung sein. Unsere Ergebnisse machen die Bedeutung biotischer Verteidigung für Pflanzen über unterschiedliche räumliche Skalen deutlich.

(C) 2015 Gesellschaft für Ökologie. Published by Elsevier GmbH. All rights reserved.

Keywords: Mutualistic interactions ;-Herbivory ;-Plant-herbivore interactions ;-Spatial scale ;·Honeydew

\footnotetext{
${ }^{*}$ Corresponding author. Tel.: +8610 62849104; fax: +86 1062849104 .

E-mail address: mkm@ rcees.ac.cn (K. Ma).
} 


\section{Introduction}

The relationship between pattern and scale is a central question in ecology (Chave 2013; Levin 1992). Scale determines how we observe, and it affects our ability to explain and predict ecological patterns and processes (Chave 2013; Levin 1992). Since the distribution of resources and the foraging patterns of consumers can vary with scale, many biotic interactions can be scale-dependent, such as pollination (Leiss \& Klinkhamer 2005; Westphal, Steffan-Dewenter, \& Tscharntke 2006), herbivory (WallisDeVries, Laca, \& Demment 1999), frugivory (Garcia, Zamora, \& Amico 2011) and seed predation (Curran and Webb 2000). The problem of the scale at which ecological processes should be considered is critical when we want to produce general predictions (Chave 2013).

Resources are often heterogeneously distributed at different scales for plants and animals (Miller, McArthur, \& Smethurst 2009; Ostoja, Schupp, \& Klinger 2013; Wilby \& Shachak 2000). Larger scales often mean more heterogeneous environments for organisms, and varied environments can lead to the change of biotic interactions (Griffin, Byrnes, \& Cardinale 2013). For example, the ecological effects of leaf-rollers can differ between leaf and plant scale (Vieira \& Romero 2013; Wang, Marquis, \& Baer 2012). On the host plant Solanum lycocarpum, the outcomes of ant-treehopper association are scale-dependent (Moreira \& Del-Claro 2005). Multiscale experimental studies are still needed to evaluate the role of scale on biotic interactions (Sandel \& Smith 2009). We are far from clear about how biotic interactions, perform across different scales especially for mutualistic interactions (Garcia et al. 2011; Miller 2014). Compared to competition and predation, the outcomes of mutualistic interactions are more likely to be context dependent (Chamberlain, Bronstein, \& Rudgers 2014).

Protective ant-plant interactions are used as model systems in the study of mutualistic interactions (Heil \& McKey 2003). In those interactions, ants protect plants from herbivores, and plants offer rewards (food body, domatia and extrafloral nectar) directly to ants, or indirectly by offering honeydew secreted by hemipterans (Chamberlain \& Holland 2009; Rico-Gray \& Oliveira 2007). Lots of studies have explicitly explored the effects of ants on plants, hemipterans and chewing insects at the branch or the whole-plant scale (Rico-Gray \& Oliveira 2007). But these studies have largely ignored the possible effects of scale because related studies often chose similar-sized branches or plants as experimental units. The possible role of scale in shaping the outcomes of ant-plant interaction has been noted recently (Chamberlain \& Holland 2009; Mortensen, Wagner, \& Doak 2011). For example, on the host plant Solanum lycocarpum, the effect of ants on the oviposition of a treehopper was negative at the wholeplant scale, but tended to be positive at the stem scale (Moreira $\&$ Del-Claro 2005). When conducting a meta-analysis on the impact ants have on plants, a study found that, compared with studies at the larger scale (whole plants), experiments at the smaller scale (leaves or branches) may overestimate the positive effects of ants on plants (Chamberlain \& Holland 2009). Another experimental study found that the defensive effects of extrafloral nectaries only worked at the stem scale rather than at the leaf scale (Mortensen et al. 2011). The role of scale in ant-plant interactions should be explicitly evaluated.

The heterogeneity of environments often increases with the enlargement of spatial scales. Larger and more structurally complex plants can hold a greater number of herbivore species because they have a greater diversity of habitats (Mopper, Maschinski, Cobb, \& Whitham 1991). It has long been noticed that, as the habitat complexity increased, more refuges can be used by herbivores, which leads to reduced prey capture rates (Crowder \& Cooper 1982). For example, when plants were cut to a simplified structure, the top-down effect of ants and spiders on herbivores became weaker (Sanders, Nickel, Grutzner, \& Platner 2008). Furthermore, the reward quality and quantity of plants for ants can vary with the size of the plant/branch (Miller 2014), which can lead to different ant-herbivore-plant interactions. For example, for the direct ant-plant interaction, the rewards for ants only occurred when plants reached a minimum size (Quintero, Barton, \& Boege 2013). As plants become larger or older, there will be a pronounced increase in the abundance of rewards; this can lead to reduced herbivory and enhanced fitness (Quintero et al. 2013). The aphid density on plants also can vary with plant size, with higher density on smaller individuals, or smaller (younger) branches within a plant (Hooks et al. 2011). Therefore, it is reasonable to predict that the ant-plant interaction mediated by aphids also can vary with plant size. But to date, few studies have tested the effect of scale and plant/branch size on the indirect ant-plant interaction mediated by honeydew-producing insects.

In this study, we evaluated the impacts of the aphid-tending ant Lasius fuliginosus on the host tree Quercus liaotungensis by experimentally excluding ants from different-size branches or trees. We hypothesized that: (1) the aphidtending ants have positive effects on plants; (2) with lower structure complexity, the ecological effects of ants should be stronger at the branch scale compared to the effects at the whole-plant scale; (3) the ecological effects of ants on smaller trees/branches should be stronger than those on larger trees/branches due to the higher density of aphids on smaller trees/branches.

\section{Materials and methods}

\section{Study site}

The study area is in the Beijing Forest Ecosystem Research Station $\left(39^{\circ} 57^{\prime} 29 \mathrm{~N}, 115^{\circ} 25^{\prime} 33 \mathrm{E}\right.$, altitude $\left.1200-1400 \mathrm{~m}\right)$ of the Chinese Ecological Research Network (CERN), located $100 \mathrm{~km}$ northwest of Beijing City, China. This area has a typically temperate, continental-monsoon climate with an 
average annual precipitation of $500-650 \mathrm{~mm}$ and an average annual temperature of $5^{\circ} \mathrm{C}$ to $10^{\circ} \mathrm{C}$. For the study site, we selected a slope in a small watershed. We chose this site because the distribution of the dominant oak tree, $Q$. liaotungensis, ranges from 1020 to $1770 \mathrm{~m}$ in elevation in this area (Zhang, Ma, Anand, \& Fu 2006). Therefore, the study site covers the middle area of the distribution range of Q. liaotungensis.

The study was conducted in a deciduous, broad-leaved forest from April to September in 2009 and 2010. The forest is an oak ( $Q$. liaotungensis) dominated, 80-year-old secondary forest with a few birches (Betula spp.), maples (Acer mono), and shrubs (e.g., Prunus spp., Vitex negundo var. hetertophylla).

\section{Ant-exclusion treatment}

In April 2009 and 2010 in the central area of the forest, we excluded ants at two scales: the branch and the whole tree of $Q$. liaotungensis. The diameter at breast height (DBH) for the selected trees ranged from 1.8 to $42.8 \mathrm{~cm}$. For ant exclusion on branches, two branches similar in size, height, and position were chosen on each tree. For ant exclusion on the whole trees, two neighboring trees (with distance $<10 \mathrm{~m}$ apart from each other) similar in DBH were selected. For each pair of branches/trees, one of the branches/trees was randomly chosen for ant-exclusion treatment and the other as a control. An adhesive of 5 to $10 \mathrm{~cm}$ in width was smeared around the base of the branch (or about $1 \mathrm{~m}$ aboveground for an individual tree) to prevent ant visitation. This adhesive was made of a polymer resin mixture (Beijing Nonghaha S \& T Co. Ltd) and was nontoxic, harmless to plants, and nonattractive to insects. The adhesive was re-smeared every two months until the end of the study. Bridges that could allow ants to climb onto ant-excluded branches or trees were cut off.

In 2009, 101 pairs of branches and 35 pairs of trees were selected. In 2010, 121 pairs of branches and 32 pairs of trees were selected. All the branch pairs were located on trees other than the trees used for tree pairs. On each tree, only one pair of branches was selected. The number of comparable trees limited the pairs of trees we could find at the study site. According to previous pitfall trap sampling, L. fuliginosus was the only ant species at high abundance at the study site, with very low abundances of Formica sinensis and Camponotus japonicus. L. fuliginosus, a typical honeydew-collecting ant species, often has facultative mutualistic relationships with aphid species (Hopkins \& Thacker 1999). In the study site, L. fuliginosus was the only ant species with higher abundance in the canopy of Q. liaotungensis (Zhang, Zhang, \& Ma 2012a), and they occupied all of the trees used in the experiment according to our observations conducted before the experimental treatment. This excluded the effect of ant occupation on a proportion of plants within their territory (Lanan \& Bronstein 2013).

\section{Evaluation of plant herbivory, herbivore abundance, and fruit production}

From late May to September in 2009 and 2010, the percentage of leaf area loss was calculated monthly. In each month, one randomly chosen twig was cut from the ant-excluded and control branches/trees. From each twig, we collected the six terminal leaves. The abundances of aphids, caterpillars, and galls were counted immediately after the cutoff of the six leaves (only in 2010). The monthly cutting of leaves may elicit induced resistance in the plants. But considering that in each month we only cut a very small proportion of the leaves of a tree (less than 15 leaves per tree), the proportion may not be large enough to trigger induced resistance at the whole-tree level.

All of the collected leaves were scanned by EPSON Perfection 4870 Photo (EPSON America, Inc., USA) and then used to calculate the percentage of leaf area loss. The herbivore-damaged parts of each leaf were repaired using Adobe Photoshop CS2 (Adobe Systems Inc., USA) according to the expected shape. The original (a) and repaired (b) areas of leaves were calculated with WinFOLIA Basic 2004a (REGENT Instruments Inc., Australia). The percentage of leaf area loss was calculated as $L[\%]=(b-a) \times 100 / b$. The anti-herbivory effect of ants was calculated as the difference between the average percentage of leaf area loss on the antexcluded and control branches of each tree. In September (2009 and 2010), which is the fruiting season of $Q$. liaotungensis, fruit numbers were counted on 10 twigs for each branch/tree.

\section{Statistical analysis}

The percentage of leaf area damage was averaged for each branch or tree in each month (the averaged value of six leaves), and these results were used in the data analysis. For herbivory, we first used one-way ANOVA to test the differences between the two years. If there was a significant difference between the two years for herbivory, then the data for each year was analyzed separately. For each year, a mixed effect model for repeated measures ANOVA was used to evaluate the effects of the ant-exclusion treatment, exclusion scale, and their interaction on the percentage of leaf area damaged. The data from different months were treated as repeated measures, and the type of the covariance structure was selected using the Akaike information criterion (AIC). Each tree was given a number, and this number (as the ID of the tree) used as a random variable. A Satterthwaite-type approximation was used to adjust the degrees of freedom for those analyses (Littell, Milliken, Stroup, Wolfinger, \& Schabenberber 2006). A generalized regression model was used to test the impacts of branch/tree size on the anti-herbivory effect of ants. The anti-herbivory effect was calculated as the difference between control and treatment. 
Because the data for aphids, caterpillars, galls and fruits are count data and non-normally distributed, models on count data were used for related analysis. Model selection was based on the Akaike information criterion (AIC). For the data on aphids, a generalized estimating equation (GEE) model for negative binomial distribution was used to analyze the effect of the ant-exclusion, exclusion scale, and their interaction on the abundance of aphids. The monthly data were treated as repeated measures, and the structure of the covariance structure was selected based on the QIC value. Then the generalized estimating equation model was used to evaluate the effects of branch size/DBH on the effect of ants on aphids. The effect of ants on aphids was calculated as the difference between control and treatment.

For the data on the number of fruits and caterpillars, there was a high frequency of zero, so a zero-inflated Poisson regression model was used to analyze the effect of antexclusion treatment, exclusion scale, and interaction. For galls, due to the over-dispersal of the data, zero-inflated negative binomial regression was used to analyze the effect of ant-exclusion treatment, exclusion scale, and interaction. There were low numbers of galls and caterpillars, so data from different months were pooled for analysis. The zero counts were modeled using a binomial logit model, and the positive counts were modeled using a Poisson distribution. The model also was used to evaluate the effects of branch size/DBH on the effect of ants on the tested variables.

\section{Results}

In total, we analyzed the percentage of herbivory for 15,944 leaves. In general, at the branch scale, the exclusion of ants resulted in a $1.52 \%$ increase in the damaged leaf area, and, at the whole-tree level, this value was $2.30 \%$ (the average value for different months). In 2009 and 2010, the treatment had a significant impact on the level of herbivory, but the anti-herbivory effect of ants was not impacted by scale, with no significant interaction effect between treatment and scale detected (Table 1, Fig. 1A and B).

For fruit production in 2009, the fruit set was very low, so only data from 2010 were used. The treatment and exclusion scales as well as their interaction had no significant impact on fruit production (Table 2, Fig. 1C). Although the fruit
Table 2. The effects of ant-exclusion (L. fuliginosus), scale and their interactions on fruit production and the abundances of aphids, caterpillars and galls on leaves of the oak tree $Q$. liaotungensis. The abundances of aphids, caterpillars and galls were the total number of each group collected from a set of six leaves (see details in Materials and methods section). For aphid, different months were used as repeated measures, $n=152$; for fruits, $n=134$; for galls and caterpillars, the data for different months were pooled for analysis, $n=711$.

\begin{tabular}{lllcr}
\hline Variable & Effect & DF & $\mathrm{Chi}^{2}$ & \multicolumn{1}{l}{$P$} \\
\hline Fruits & Treatment & 1 & 0.02 & 0.8756 \\
& Scale & 1 & 2.71 & 0.0997 \\
& $\mathrm{~T} \times \mathrm{S}$ & 1 & 0.00 & 0.9733 \\
Aphids & Treatment & 1 & 15.73 & $<\mathbf{0 . 0 0 0 1}$ \\
& Scale & 1 & 0.15 & 0.6949 \\
& T $\times \mathrm{S}$ & 1 & 0.48 & 0.4880 \\
Caterpillars & Treatment & 1 & 1.63 & 0.2016 \\
& Scale & 1 & 0.21 & 0.6477 \\
& T $\times \mathrm{S}$ & 1 & 0.08 & 0.7802 \\
Galls & & & & \\
& Treatment & 1 & 7.49 & $<\mathbf{0 . 0 0 6 2}$ \\
& Scale & 1 & 1.71 & 0.1904 \\
& T $\times \mathrm{S}$ & 1 & 0.25 & 0.6175 \\
\hline
\end{tabular}

production for treated branches in 2010 was much higher than that for control branches, but the difference is insignificant (Chi-square $=2.56 ; \mathrm{DF}=1 ; P=0.1097$ ).

Ants significantly enhanced the abundance of aphids (Table 2, Fig. 1D), but this positive effect on aphids was not changed across scales (Table 2). The abundance of caterpillars on leaves was not significantly affected by the treatment, exclusion scale, or their interaction (Table 2, Fig. 1E). Ants reduced the abundance of galls significantly, but scale and their interaction with ants had no significant effect on the abundance of galls (Table 2, Fig. 1F).

Of the five tested variables, none was affected by the size of the branch or tree. The effect of ants on herbivory, fruit production, and the positive effect of ants on aphids had no relationship with the size of the branch or tree (Fig. 2, with all $P>0.1)$.

Table 1. The effects of ant-exclusion (L. fuliginosus), scale and their interactions on the percentage of leaf area loss in the oak tree $Q$. liaotungensis.

\begin{tabular}{|c|c|c|c|c|c|c|}
\hline Variable & Year & Effect & Num DF & Den DF & $F$ value & $P$ \\
\hline \multirow[t]{6}{*}{ Herbivory } & \multirow[t]{3}{*}{2009} & Treatment & 1 & 122 & 41.40 & $<0.0001$ \\
\hline & & Scale & 1 & 122 & 2.66 & 0.1504 \\
\hline & & $\mathrm{T} \times \mathrm{S}$ & 1 & 128 & 1.56 & 0.2140 \\
\hline & \multirow[t]{3}{*}{2010} & Treatment & 1 & 147 & 16.11 & $<0.0001$ \\
\hline & & Scale & 1 & 141 & 4.83 & 0.0296 \\
\hline & & $\mathrm{T} \times \mathrm{S}$ & 1 & 147 & 0.48 & 0.4898 \\
\hline
\end{tabular}



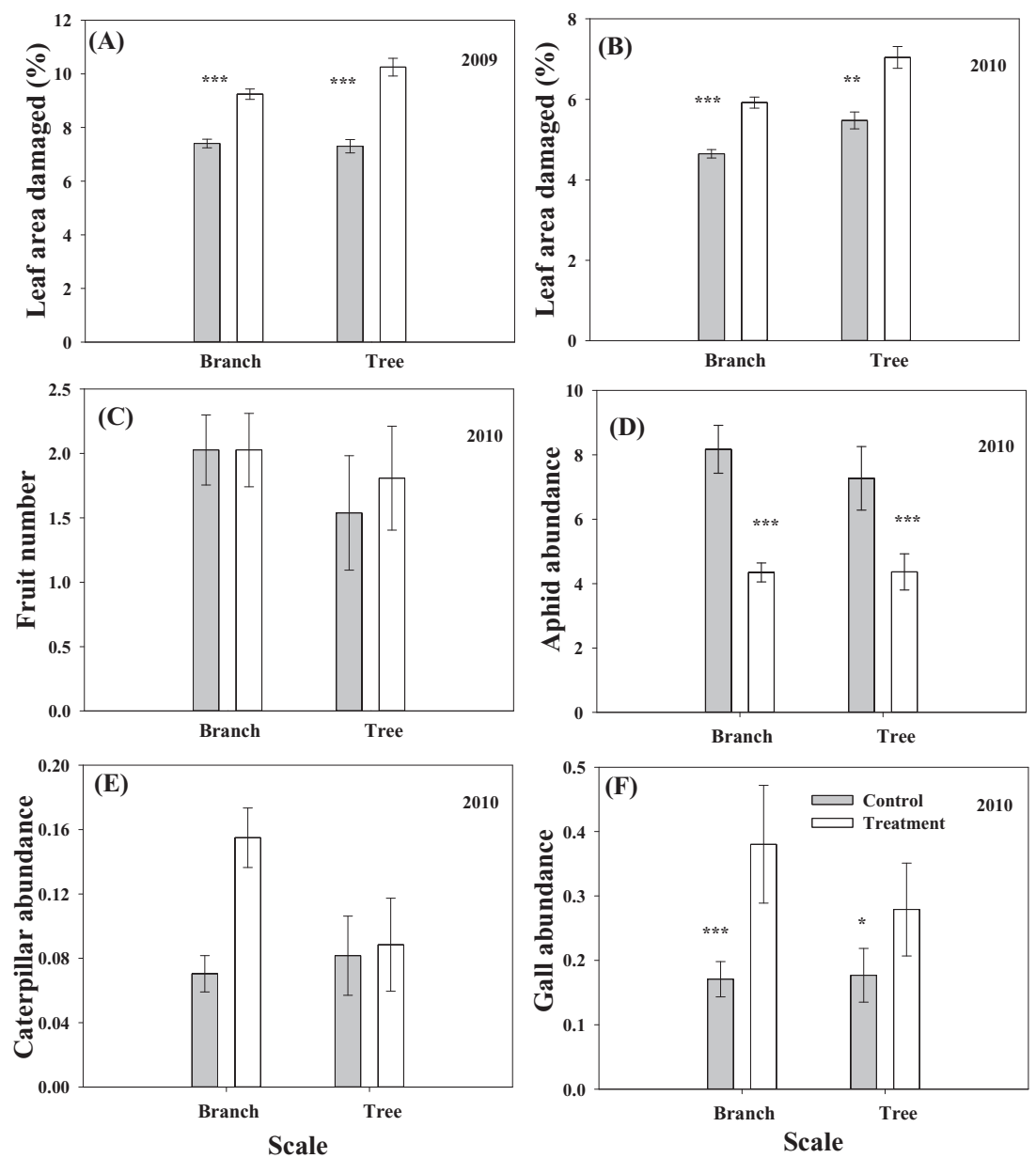

Fig. 1. The ecological effects of the ant-exclusion treatment on the herbivory, fruit production and the abundance of herbivores on the oak tree $Q$. liaotungensis at the branch and whole-tree scale (Mean, SE). * Denotes $P<0.05$, ** denotes $P<0.01$, *** denotes $P<0.001$.

\section{Discussion}

As crucial nodes in the structure of communities, plant-animal interactions are pivotal drivers of ecosystem functioning (Bascompte \& Jordano 2007; Burkle, Marlin, \& Knight 2013; Dattilo et al. 2014), but we are far from clear about how these interactions perform at different scales (Garcia et al. 2011; Van de Koppel et al. 2005). Taking ant-aphid-plant interaction as a model system, we found that the effects of ants on plants were consistent across different scales. The results extend our understanding of the ecological effects of mutualistic interactions in a community.

Several recent studies suggest that biotic interactions can vary with scales, but our study is contradictory to those studies. (Garcia et al. 2011; Griffin et al. 2013; Miller 2014; Mortensen et al. 2011; Vilela, Torezan-Silingardi, \& Del-Claro 2014). With a similar experimental design, a previous study found a significant anti-herbivory effect of an ant-treehopper association at both plant and stem scales, but the relative strength of the effect at the two scales had not been explicitly compared (Moreira \& Del-Claro 2005). Two reasons can explain the patterns found in our study. First, aphids were homogenously distributed across different scales. The distribution of aphids determines the distribution pattern of ants in a canopy. In our study, most $(82.5 \%)$ of the leaf samples (combining six leaves) had aphids; this can lead to the pervasive distribution of ants in the canopy, regardless of the scale. We also found no significant impacts of scale on the abundances of caterpillars and galls in this study. Thus, with ants and herbivores homogenously distributed at different scales, it is not surprising that the outcomes of their interactions were independent of scale. Second, within each scale, aphids were also homogenously distributed on different sized trees/branches. The heterogeneous distribution of resources over different parts within a certain scale can shape the outcome of ant-plant interaction. In the direct ant-plant interaction, some high-quality rewards for ants only occur on young leaves, twigs, or larger segments within a tree (Miller 2014; Pringle, Dirzo, \& Gordon 2011). In some cases, ant densities on larger trees are lower than the densities on smaller ones, which can lead to the varied effects of ants on plants on different-sized trees (Palmer \& Brody 2013; Palmer et al. 2010; Pringle, Dirzo, \& Gordon 2012). Different from those previous researches on direct ant-plant 

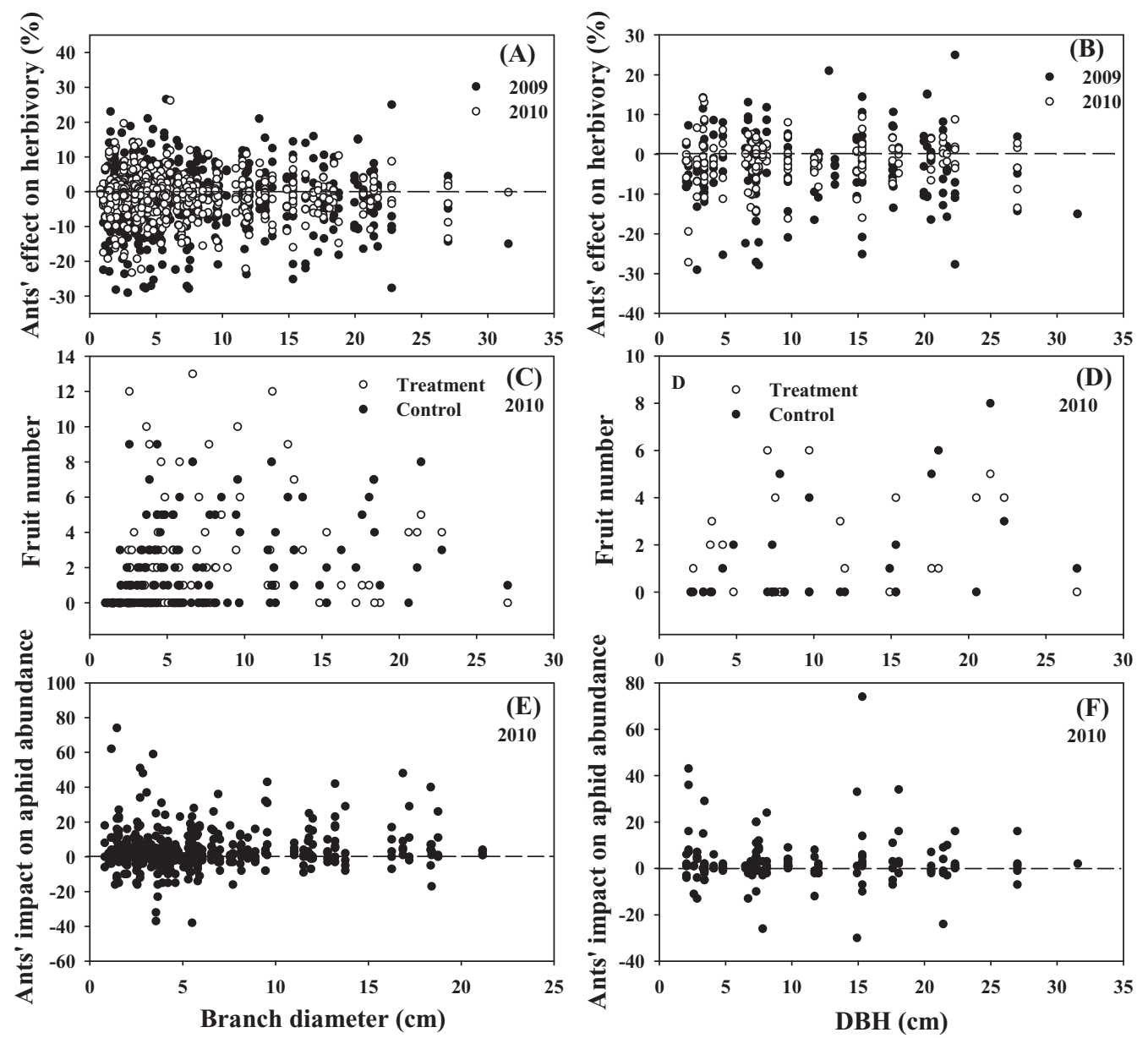

Fig. 2. The relationship between the effects of the ant-exclusion treatment on the herbivory, fruit production, the abundance of aphids on the oak tree $Q$. liaotungensis and the size (branch or $\mathrm{DBH}$ ) of the experimental unit. * Denotes $P<0.05$, ** denotes $P<0.01$, *** denotes $P<0.001$.

interaction, aphids, being the key factor attracting ants in the canopy, were homogenously distributed across and within different scales in our study. Thus the homogenous distribution of aphids can be the key reason for the scale-independent effect of the indirect ant-plant interaction as we have shown here.

Our study suggests that the ecological effects of biotic interactions can remain consistent across different scales. For ant-plant interactions, most studies tend to choose similarsized branches or trees to exclude the potential influences of scale. Our results suggest this type of experimental design may be unnecessary. A previous meta-analysis suggested that future studies should avoid treatment application below the whole-plant level (Chamberlain \& Holland 2009). But through explicit study, we show that it may be unnecessary to do this in the indirect ant-plant interaction mediated by aphids. The pervasive distribution of aphids can make the ant-herbivore conflict unavoidable at different scales. It should be noted that the scale in our study has its limitations: the ant-plant interaction on even smaller or larger scales has not been evaluated. At the smaller scale, the effect of ants on different leaves vary (Fagundes, Ribeiro, \& Del-Claro
2013; Pringle et al. 2011). At the even larger scale, larger trees or bigger patches of resources can have an impact on the distribution of ant nests in a field (Wagner \& Nicklen 2010). The spatial variation of resources and ant colonies at a large scale can have a deep impact on ant-plant interactions. Consistent with a previous meta-analysis (Zhang, Zhang, \& Ma 2012b), the anti-herbivory effect of ants didn't translate to increased fruit production in this study. One reason for this result may be that the increased abundances of aphids through ant tending can decrease growth and reproduction of plants (Zvereva, Lanta, \& Kozlov 2010). Furthermore, some plants can suffer certain levels of herbivory without reducing their fitness (Stowe, Marquis, Hochwender, \& Simms 2000). In 2010, ants significantly reduced the herbivory, but not the abundances of caterpillars on canopy. In some cases, ants can disturb the feeding of caterpillars on canopy but not dispel them away from leaves (Oliveira \& Freitas 2004); some caterpillars have special defensive mechanisms against ants when feeding on plants (Oliveira $\&$ Freitas 2004). Therefore, its possible that ants can reduce herbivory through impeding the feeding of caterpillars, rather than reducing their abundances on plants. Two previous 
studies suggest that butterflies can avoid laying eggs on plant parts with ants (Freitas \& Oliveira 1996; Sendoya, Freitas, \& Oliveira 2009). Both of these studies were conducted within plant scale (branches and leaves); our study suggests that this also can be the case at the whole-plant scale.

In conclusion, our study showed that the effects of ant-aphid mutualism on plants are consistent within and among individual plants. The finding highlights the importance of biotic defense for plants across different spatial scales. The distribution pattern of resources should be considered the key factor in shaping the outcome of biotic interactions at different scales in future studies.

\section{Acknowledgements}

This work was supported by National Natural Science Foundation of China (31300368, 31370451). We thank Zhenghui $\mathrm{Xu}$ and Gexia Qiao for ant- and aphid-species identification.

\section{References}

Bascompte, J., \& Jordano, P. (2007). Plant-animal mutualistic networks: The architecture of biodiversity. Annual Review of Ecology, Evolution, and Systematics, 38, 567-593.

Burkle, L. A., Marlin, J. C., \& Knight, T. M. (2013). Plant-pollinator interactions over 120 years: Loss of species, co-occurrence, and function. Science, 339, 1611-1615.

Chamberlain, S. A., Bronstein, J. L., \& Rudgers, J. A. (2014). How context dependent are species interactions? Ecology Letters, 17, 881-890.

Chamberlain, S. A., \& Holland, J. N. (2009). Quantitative synthesis of context dependency in ant-plant protection mutualisms. Ecology, 90, 2384-2392.

Chave, J. (2013). The problem of pattern and scale in ecology: What have we learned in 20 years? Ecology Letters, 16, 4-16.

Crowder, L. B., \& Cooper, W. E. (1982). Habitat structural complexity and the interaction between bluegills and their prey. Ecology, 63, 1802-1813.

Curran, L. M., \& Webb, C. O. (2000). Experimental tests of the spatiotemporal scale of seed predation in mast-fruiting dipterocarpaceae. Ecological Monographs, 70, 129-148.

Dattilo, W., Fagundes, R., Gurka, C. A. Q., Silva, M. S. A., Vieira, M. C. L., Izzo, T. J., et al. (2014). Individual-based ant-plant networks: Diurnal-nocturnal structure and species-area relationship. PLOS ONE, 9, 1-9.

Fagundes, R., Ribeiro, S. P., \& Del-Claro, K. (2013). Tending-ants increase survivorship and reproductive success of Calloconophora pugionata Drietch (Hemiptera, Membracidae), a trophobiont herbivore of Myrcia obovata O. Berg (Myrtales, Myrtaceae). Sociobiology, 60, 11-19.

Freitas, A. V. L., \& Oliveira, P. S. (1996). Ants as selective agents on herbivore biology: Effects on the behaviour of a non-myrmecophilous butterfly. Journal of Animal Ecology, 65, 205-210.
Garcia, D., Zamora, R., \& Amico, G. C. (2011). The spatial scale of plant-animal interactions: Effects of resource availability and habitat structure. Ecological Monographs, 81, 103-121.

Griffin, J. N., Byrnes, J. E. K., \& Cardinale, B. J. (2013). Effects of predator richness on prey suppression: A meta-analysis. Ecology, 94, 2180-2187.

Heil, M., \& McKey, D. (2003). Protective ant-plant interactions as model systems in ecological and evolutionary research. Annual Review of Ecology Evolution and Systematics, 34, 425-453.

Hooks, C. R. R., Wang, K. H., Pradhan, N. C., Manandhar, R., Wright, M. G., \& Vorsino, A. (2011). Population distribution and density of Pentalonia nigronervosa (Hemiptera: Aphididae) within banana mats: Influence of plant age and height on sampling and management. Journal of Economic Entomology, 104, 947-955.

Hopkins, G. W., \& Thacker, J. I. (1999). Ants and habitat specificity in aphids. Journal of Insect Conservation, 3, 25-31.

Lanan, M. C., \& Bronstein, J. L. (2013). An ant's-eye view of an ant-plant protection mutualism. Oecologia, 172, 779-790.

Leiss, K. A., \& Klinkhamer, P. G. L. (2005). Spatial distribution of nectar production in a natural Echium vulgare population: Implications for pollinator behaviour. Basic and Applied Ecology, 6, 317-324.

Levin, S. A. (1992). The problem of pattern and scale in ecology. Ecology, 73, 1943-1967.

Littell, R. C., Milliken, G. A., Stroup, W. W., Wolfinger, R. D., \& Schabenberber, O. (2006). SAS for mixed models (2nd ed.). SAS, Institute, Inc.

Miller, A. M., McArthur, C., \& Smethurst, P. J. (2009). Spatial scale and opportunities for choice influence browsing and associational refuges of focal plants. Journal of Animal Ecology, 78, 1134-1142.

Miller, T. E. X. (2014). Plant size and reproductive state affect the quantity and quality of rewards to animal mutualists. Journal of Ecology, 102, 496-507.

Mopper, S., Maschinski, J., Cobb, N., \& Whitham, T. G. (1991). A new look at habitat structure: Consequences of herbivoremodified plant architecture. In S. Bell, E. McCoy, \& H. Mushinsky (Eds.), Habitat structure (pp. 260-280). Netherlands: Springer.

Moreira, V. S. S., \& Del-Claro, K. (2005). The outcomes of an ant-treehopper association on Solanum lycocarpum St. Hill: Increased membracid fecundity and reduced damage by chewing herbivores. Neotropical Entomology, 34, 881-887.

Mortensen, B., Wagner, D., \& Doak, P. (2011). Defensive effects of extrafloral nectaries in quaking aspen differ with scale. Oecologia, 165, 983-993.

Oliveira, P. S., \& Freitas, A. V. L. (2004). Ant-plant-herbivore interactions in the neotropical cerrado savanna. Naturwissenschaften, 91, 557-570.

Ostoja, S. M., Schupp, E. W., \& Klinger, R. (2013). Seed harvesting by a generalist consumer is context-dependent: Interactive effects across multiple spatial scales. Oikos, 122, 563-574.

Palmer, T. M., \& Brody, A. K. (2013). Enough is enough: The effects of symbiotic ant abundance on herbivory, growth, and reproduction in an African acacia. Ecology, 94, 683-691.

Palmer, T. M., Doak, D. F., Stanton, M. L., Bronstein, J. L., Kiers, E. T., Young, T. P., et al. (2010). Synergy of multiple partners, including freeloaders, increases host fitness in a multispecies mutualism. Proceedings of the National Academy of Sciences of the United States of America, 107, 17234-17239. 
Pringle, E., Dirzo, R., \& Gordon, D. (2011). Indirect benefits of symbiotic coccoids for an ant-defended myrmecophytic tree. Ecology, 92, 37-46.

Pringle, E. G., Dirzo, R., \& Gordon, D. M. (2012). Plant defense, herbivory, and the growth of Cordia alliodora trees and their symbiotic Azteca ant colonies. Oecologia, 170, 677-685.

Quintero, C., Barton, K. E., \& Boege, K. (2013). The ontogeny of plant indirect defenses. Perspectives in Plant Ecology, Evolution and Systematics, 15, 245-254.

Rico-Gray, V., \& Oliveira, P. S. (2007). The ecology and evolution of ant-plant interactions (1st ed.). Chicago, IL: University of Chicago Press.

Sandel, B., \& Smith, A. B. (2009). Scale as a lurking factor: Incorporating scale-dependence in experimental ecology. Oikos, 118 , 1284-1291.

Sanders, D., Nickel, H., Grutzner, T., \& Platner, C. (2008). Habitat structure mediates top-down effects of spiders and ants on herbivores. Basic and Applied Ecology, 9, 152-160.

Sendoya, S. F., Freitas, A. V. L., \& Oliveira, P. S. (2009). Egglaying butterflies distinguish predaceous ants by sight. American Naturalist, 174, 134-140.

Stowe, K. A., Marquis, R. J., Hochwender, C. G., \& Simms, E. L. (2000). The evolutionary ecology of tolerance to consumer damage. Annual Review of Ecology and Systematics, 31, $565-595$.

Van de Koppel, J., Bardgett, R. D., Bengtsson, J., RodriguezBarrueco, C., Rietkerk, M., Wassen, M. J., et al. (2005). The effects of spatial scale on trophic interactions. Ecosystems, 8, 801-807.

Vieira, C., \& Romero, G. Q. (2013). Ecosystem engineers on plants: Indirect facilitation of arthropod communities by leaf-rollers at different scales. Ecology, 94, 1510-1518.
Vilela, A. A., Torezan-Silingardi, H. M., \& Del-Claro, K. (2014). Conditional outcomes in ant-plant-herbivore interactions influenced by sequential flowering. Flora, 209, 359-366.

Wagner, D., \& Nicklen, E. F. (2010). Ant nest location, soil nutrients and nutrient uptake by ant-associated plants: Does extrafloral nectar attract ant nests and thereby enhance plant nutrition? Journal of Ecology, 98, 614-624.

WallisDeVries, M. F., Laca, E. A., \& Demment, M. W. (1999). The importance of scale of patchiness for selectivity in grazing herbivores. Oecologia, 121, 355-363.

Wang, H. G., Marquis, R. J., \& Baer, C. S. (2012). Both host plant and ecosystem engineer identity influence leaf-tie impacts on the arthropod community of Quercus. Ecology, 93, 2186-2197.

Westphal, C., Steffan-Dewenter, I., \& Tscharntke, T. (2006). Bumblebees experience landscapes at different spatial scales: Possible implications for coexistence. Oecologia, 149, 289-300.

Wilby, A., \& Shachak, M. (2000). Harvester ant response to spatial and temporal heterogeneity in seed availability: Pattern in the process of granivory. Oecologia, 125, 495-503.

Zhang, S., Zhang, Y., \& Ma, K. (2012). Disruption of ant-aphid mutualism in canopy enhances the abundance of beetles on the forest floor. PLOS ONE, 7, e35468.

Zhang, S., Zhang, Y. X., \& Ma, K. M. (2012). The ecological effects of the ant-hemipteran mutualism: A meta-analysis. Basic and Applied Ecology, 13, 116-124.

Zhang, Y. X., Ma, K. M., Anand, M., \& Fu, B. J. (2006). Do generalized scaling laws exist for species abundance distribution in mountains? Oikos, 115, 81-88.

Zvereva, E. L., Lanta, V., \& Kozlov, M. V. (2010). Effects of sapfeeding insect herbivores on growth and reproduction of woody plants: A meta-analysis of experimental studies. Oecologia, 163, 949-960.

Available online at www.sciencedirect.com 